\title{
Mapping historical landscape changes with the use of a space- time cube
}

\author{
Edyta P. Bogucka, ${ }^{\text {a Mathias Jahnke }}{ }^{\mathrm{a}}$ \\ ${ }^{a}$ Chair of Cartography, Technical University of Munich, Munich, Germany; \\ e.p.bogucka@tum.de, mathias.jahnke@tum.de
}

\begin{abstract}
In this contribution, we introduce geographic concepts in the humanities and present the results of a spacetime visualization of ancient buildings over the last centuries. The techniques and approaches used were based on cartographic research to visualize spatio-temporal information. As a case study, we applied cartographic styling techniques to a model of the Royal Castle in Warsaw and its different spatial elements, which were constructed and destroyed during their eventful history. In our case, the space-time cube approach seems to be the most suitable representation of this spatio-temporal information. Therefore, we digitized the different footprints of the castle during the ancient centuries as well as the landscape structure around, and annotated them with monarchies, epochs and time. During the digitization process, we had to cope with difficulties like sources in various scales and map projections, which resulted in varying accuracies. The results were stored in KML to support a wide variety of visualization platforms.
\end{abstract}

Keywords: digital humanities, space-time cube, Google Earth, KML

\section{Introduction}

The proposal of reintroducing geographic concepts of space into the humanities started the phenomenon described as a "spatial turn" in digital humanities (Soja 1989, Schlögel 2003). These approaches led to the development of GISbased applications in various fields of humanities research, such as history, economy and sociology (Bodenhamer et al. 2010, Gregory et al. 2014). At the same time geographers have raised concerns about the limitations of geo-spatial technologies in complexities of the human organization in space and time (Janelle 2001). After years of interdisciplinary research, creating efficient exploration tools for spatiotemporal datasets and presenting them in cognitively supportive visualizations still remains a major challenge for researchers in the humanities (Bruggmann and Fabrikant 2016).

This study investigates to what degree spatial digital humanities can benefit from open-source movements to create, interactively visualize and explore spatiotemporal datasets.

The idea of a space-time cube was developed by Hägerstrand (1970) and originates from humanities research focused on social interactions and human movements in space and time (Kveladze et al. 2013). Within the space-time cube, the two-dimensional geographical space is represented by the base of the cube (Gatalsky et al. 2010), while time is considered as the third, vertical dimension (cube's height).

Cultural heritage research has adapted the ideas of the space-time cube as one of the methods of challenging and enhancing the previous knowledge. Kraak and Koussoulakou (2004) considered the space-time cube as a possible exploration tool for deriving the spatiotemporal characteristics of archaeological sites. Furthermore, the use of the space-time cube in humanities research is not limited to geodata visualizations. Windhager and Mayr (2012) have extended the idea of the space-time cube within their conceptual framework into a 'Cultural Heritage Cube' for visual exhibition exploration.

\section{Study Area, Data Sources and Methods}

As a case study the Royal Castle in Warsaw, a UNESCO World Heritage Site since 1980, was chosen, due to its eventful history. The residence consists of different spatial elements, e.g., the castle itself, the Kubicki Arcades, two gardens and a Tin-Roofed Palace (Fig.1). Initially used as dukes and kings headquarter, today the residence serves as the national museum. During the last 600 years the castle underwent huge changes. Large scale expansions in the cause of the 16th and 17th century, significant destructions in the 17th and 19th century and the complete destruction during the World War II (Fig.2). To visualize the eventful history of the castle the spacetime cube visualization is used within Google Earth, allowing the tracking of the changes of historical objects in time to examine the periods of expansion, destruction, rebuilding and renovation. This required the simultaneous view of both space and time. 


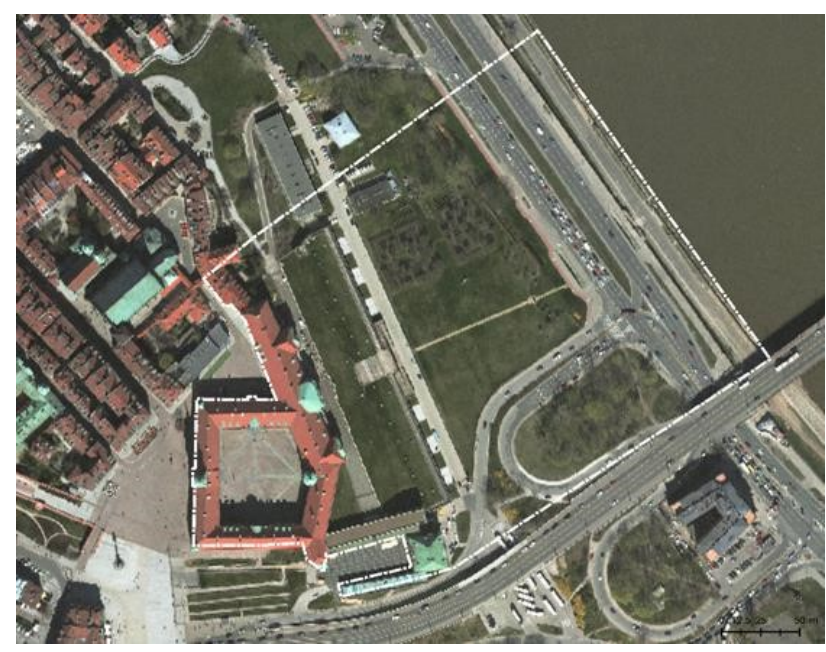

Fig. 1. Location of the research area with the ortophotomap background acquired in 2011 - boundaries marked with the white dashed line. (Background map source: Office of Surveying and Cadastre, Warsaw: www.mapa.um.warszawa.pl)

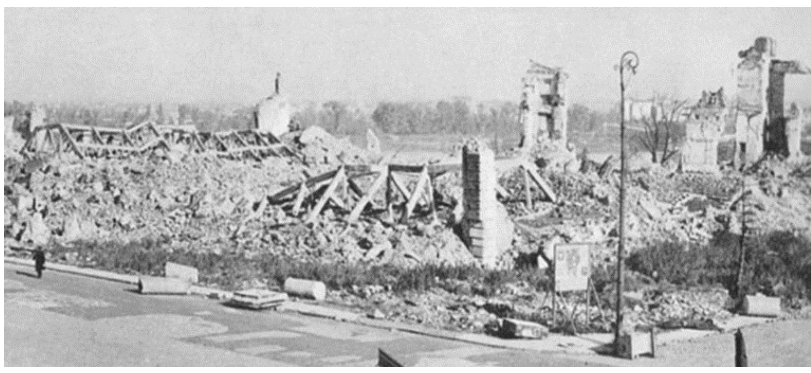

Fig. 2. Ruins of the Royal Castle in 1945. (Source: National Digital Archives, www.nac.gov.pl)

The creation of meaningful spatiotemporal visualization for humanities specialists involves not only cartographic design approaches but also data processing and management. Previous research on space-time cubes has focused mainly on point and polyline features to visualize states or paths within a certain timeframe (Gatalsky et al. 2010, Kveladze et al. 2013). A major issue of creating spatiotemporal visualizations for geo-historical data is to cope with detailed scale analyses of polygon features that have been chosen for representing the buildings at different epochs. Fundamental elements of the landscape structure were examined from the period between ca. 1350 - 2015 with the use of graphical schemas, historical maps, photoplans, and ortophotomaps.

These graphical schemas, historical maps, photoplans, and ortophotomaps were obtained from the Department of Archeological Researches, Royal Castle in Warsaw, the National Library of Poland ${ }^{1}$ and the Office of Surveying and Cadastre ${ }^{2}$ in digitized raster formats. Therefore, clipping raster data to the area of interest as well as georeferencing was necessary.

Meanings of symbols and cartographic representation of the historical maps covering the area of Warsaw have been partly described by Gromski (1997) and Bartoszewicz (2003, 2008). Based on this information, the following landuse classes were distinguished: buildings, small architecture objects (e.g., defense walls, monuments), water bodies (rivers, streams), greenery and city squares. For each historical map, corresponding features were manually digitized and described with additional metadata.

KML, a XML notation for storing and visualizing geographic data and associated content was chosen for this study. With KML, a well-recognized exchange format, a variety of viewers for multiple platforms are available, such as Google Earth.

\section{Results}

Obtained results demonstrate the universal use of the space-time cube for the dynamic visualization of historical data. Features representing the landscape elements are represented vertically on the Z-axis. The earliest historical objects are placed at the top of the cube, while the latest ones are closer to the cube's bottom (ground level). Fig. 4 shows the first stage of the data exploration through the time slider and pop-up windows. Users can change their view perspective by zooming, panning and rotating the cube and pointing the certain date on the time slider. To enhance the understanding of historical landscape, buildings are symbolized according to the century they originate from (Fig.5). For the buildings mentioned on the oldest and most uncertain historical sources, special links are created to point their approximate location on the current map. This allows the identification of expansion, destruction, rebuilding and renovation phases of the castle residence as well as tracking the spatial dimensions of those changes through time (Fig.6). The space-time cube reveals events influencing both anthropogenic and natural landscape elements as shifting the Vistula river shores between the 14 th and 18th century. The features were additionally described by time labels indicating the duration of centuries.

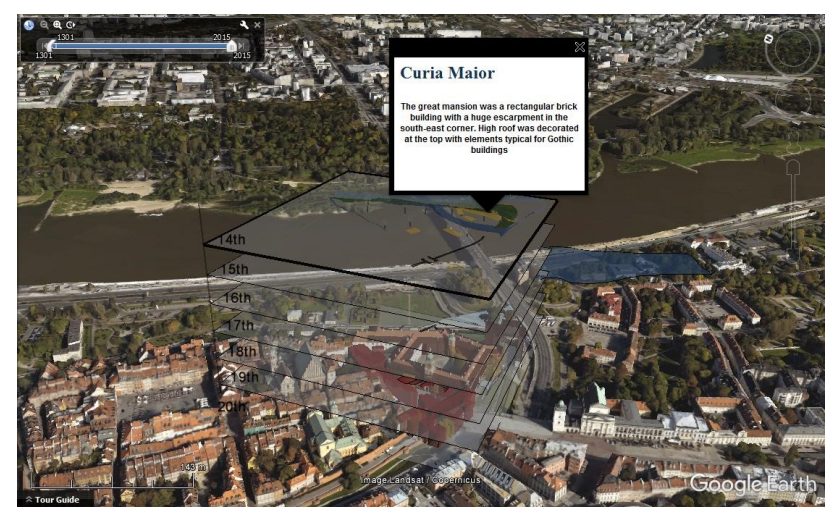

Fig. 4. Dataset exploration through the time slider and description in a pop-up window.

\footnotetext{
${ }^{1}$ www.polona.pl

${ }^{2}$ www.mapa.um.warszawa.pl
} 

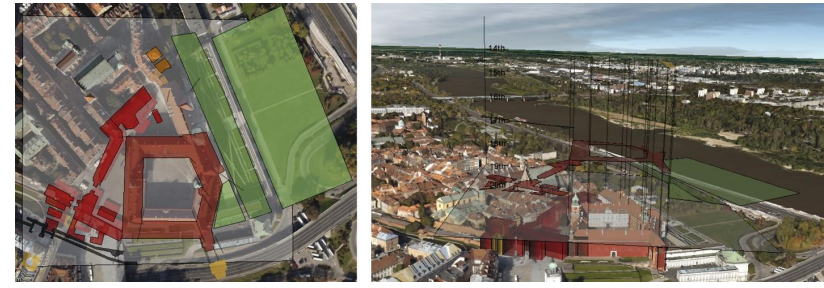

Fig. 5. The overview of the study area in 1800 as a compilation of different historical objects.
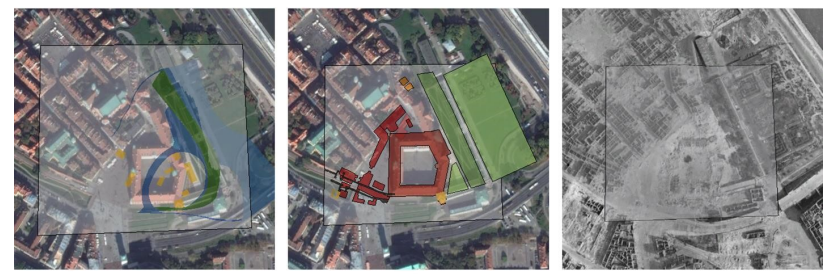

Fig. 6. Landscape structure in 1300, 1805 and 1945.

\section{Acknowledgements}

We are grateful to the experts from Royal Castle in Warsaw - Museum, who provided historical data, insight and expertise that greatly assisted the research.

The study was based on source materials available in Poland in the public domain, which meet the criteria for reuse in accordance with the Act of 6 September 2001 on Access to Public Information (Dz. U. of 2014., Pos. 782, as amended).

\section{References}

Bartoszewicz, H. (2003). Rozwój przestrzenny Warszawy w latach 1800-1914 w wietle róde kartograficznych. Mazowieckie Studia humanistyczne. 9/1 (2), 165-187.

Bartoszewicz, H. (2008). Zbiory kartograficzne Archiwum Gównego Akt Dawnych w Warszawie. Polski Przegld Kartograficzny, 40(2), 144-157.

Bodenhamer, D. J, Corrigan, J., Harris, T. M. (Ed.) (2010). The Spatial Humanities. GIS and the future of humanities scholarschip. Bloomington \& Indianapolis: Indiana University Press.

Bruggmann A., Fabrikant, S.I. (2016). How does GIScience support spatio-temporal information search in the humanities? Spatial Cognition \& Computation.

Gatalsky, P., Andrienko, N., Andrienko, G. (2010). Interactive Analysis of Event Data Using Space-Time Cube. Proceedings of the Eighth International Conference on Information Visualization.

Gregory, I.N., Geddes, A. (Ed.) (2014). Toward Spatial Humanities: Historical GIS and Spatial History. Bloomington \& Indianapolis: Indiana University Press.

Gromski, J. (1997). Plany Warszawy i mapy okolic Warszawy w zbiorach Muzeum Historycznego m.st.Warszawy. Almanach Muzelany. 1, 263-284.

Kraak, M.-J., Koussoulakou, A. (2004). A visualization environment for the space-time cube. In: Leicester. P.F. Fisher (ed.), SDH 2004: Proceedings of the 11th
International Symposium on Spatial Data Handling: Advances in Spatial Data Handling II, August 23-25, 2004, University of Berlin, Springer, Germany. 189200.

Hägerstrand, T. (1970). What about people in regional science? Papers in Regional Science Association. 24, 7 21.

Janelle, D.G. (2001). Time-space in geography. In N.J. Smelser and P.B. Baltes, eds. International encyclopedia of the social and behavioral sciences (pp. 1574615749). Amsterdam: Pergamon-Elsevier Science.

Kveladze, I., Kraak, M-J., P.J.M. van Elzakker, C. (2013). A Methodological Framework for Researching the Usability of the SpaceTime Cube. The Cartographic Journal. Vol. 50, Iss. 3, pp. 201-210.

Schlögel, K. (2003). Im Raume lesen wir die Zeit: Über Zivilisationsgeschichte und Geopolitik. München: Carl Hanser Verlag. Great Britain: Biddles Ltd.

Soja, W. E. (1989). Postmodern Geographies. The Reassertion of Space in Critical Social Theory.

Windhager, F., Mayr, E. (2012). Cultural Heritage Cube. A conceptual framework for visual exhibition exploration. Proceedings of the 16th International Conference on Information Visualization. 